Full Title

\title{
CD43Lo classical monocytes participate in the cellular immune response to isolated primary blast lung injury
}

Running Title

CD43Lo classical monocytes in primary blast lung injury

Ashton Barnett-Vanes ${ }^{1,3} \mathrm{Ph} . \mathrm{D}$,

Anna Sharrock ${ }^{1,3}$, MRCS,

Theofano Eftaxiopoulou ${ }^{2,3} \mathrm{PhD}$,

Hari Arora ${ }^{2,3} \mathrm{PhD}$,

Warren Macdonald ${ }^{2,3} \mathrm{PhD}$,

Anthony MJ Bull ${ }^{2,3} \mathrm{PhD}$, FREng,

Sara M Rankin ${ }^{1,3} \mathrm{PhD}$.

1. Inflammation, Repair and Development Section, Respiratory Sciences Division, National Heart and Lung Institute, Imperial College London, UK

2. Department of Bioengineering, Imperial College London, UK

3. Royal British Legion Centre for Blast Injury Studies, Imperial College London, UK

Work conducted at Inflammation, Repair and Development Section, Respiratory Sciences Division, National Heart and Lung Institute, Imperial College London and Department of Bioengineering, Imperial College London, UK under the auspices of Royal British Legion Centre for Blast Injury Studies, Imperial College London, UK.

Reprints should be addressed to:

The Centre for Blast Injury Studies

Department of Bioengineering

Imperial College London

South Kensington Campus

London, SW7 2AZ

No reprints will be ordered.

This study was funded by grants from the Centre for Blast Injury Studies funded by Imperial College London and the Royal British Legion.

Conflict of interest Statements

ABV: Nothing to declare

AS: Nothing to declare

TE: Nothing to declare

HA: Nothing to declare

WM: Nothing to declare

AB: Nothing to declare

SR: Nothing to declare 


\section{Background}

Explosive blast trauma occurs by four mechanisms: primary injuries are due to the isolated effect of the blast wave on the human body, secondary injuries are due to damage from fragments energised from the explosion, tertiary injuries result from acceleration of the body against an object or through the explosion energising hard materials in a solid form (not fragments) and encroaching upon the person, and quaternary injuries describe other physical insults, including burns and smoke inhalation ${ }^{1}$.

Gas-containing organs such as the lungs are particularly susceptible to barotrauma, and 'Primary Blast Lung Injury' (PBLI) is a commonly reported injury amongst blast casualties. A review of terrorist bombings worldwide found the incidence of PBLI in immediate fatalities to be as high as $47 \%{ }^{2}$; whilst in a review of military blast casualties that survived to emergency admission, PBLI was found in $11.2 \%$ of 648 blast casualties. In this series, $16.2 \%$ of mounted and $17.1 \%$ of dismounted injuries developed PBLI, which was significantly associated with increased mortality ${ }^{3,4}$.

Laboratory investigations of PBLI have sought to recapitulate the injury under experimental conditions. Studies investigating the subsequent immune response have been reported most commonly in rats ${ }^{5-10}$, mice ${ }^{11-15}$ and swine ${ }^{16,17}$. These studies have offered overwhelming evidence of the neutrophil response to PBLI in animal models, with increases in circulating and broncho-alveolar lavage fluid (BALF) neutrophils, increases in Myeloperoxidase (MPO) activity in the lung, and neutrophil staining by histology 9-12,14,18,19. However, the immune response to tissue damage differs depending on the type of organ injured and their local physiology; it remains unclear what specific contribution blast injuries to different parts of the body make to the inflammatory response that ensues. Whilst most clinically blast injured patients are polytraumatised, discerning these interacting immune responses experimentally is necessary for translational studies seeking to better understand, monitor or attenuate the immune response in blast trauma.

Further, knowledge of the role played by other immune cells to PBLI is limited - no study has characterised the full repertoire of immune cells in PBLI; specifically, the involvement of monocytes in PBLI remains unclear. These cells are frequently recruited to sites of inflammation; in humans they are characterised by differential CD14 and CD16 expression ${ }^{20}$, in mice by CCR2, CX3CR1 and Ly6C ${ }^{21,22}$ and in rats by CD43 alone or in conjunction with His48 ${ }^{23}$. In rats, CD43 Hi and Lo monocytes are considered to be analogous to the Ly6C Lo (Non-classical) and Ly6C Hi (Classical) murine monocytes respectively. Classical Ly6C Hi monocytes are recruited to tissues in sterile ${ }^{24}$ and infectious ${ }^{25}$ models of inflammation. There, they can differentiate into inflammatory macrophages and dendritic cells, amplifying or resolving inflammation. In rats, circulating monocyte subsets are activated by inflammatory stimuli ${ }^{26}$, respond differentially to sterile danger signals sub-acutely ${ }^{27}$, and have been shown to migrate to the lung in LPS-induced pulmonary inflammation ${ }^{23}$. Moreover, there is growing evidence that inflammation to localised trauma may 'spill-over', causing immune effects at uninjured distal organs. This has been documented in models of blast limb trauma ${ }^{28,29}$ and PBLI has been associated with immune changes in the spleen ${ }^{15,30}$.

Accordingly, the aim of this study was to utilise a rodent model to investigate the cellular immune response elicited from an isolated primary blast lung injury alone. We hypothesized 
that an isolated PBLI would elicit an acute monocytic - in addition to neutrophilic - response; we sought to delineate whether this monocyte response was subset selective; if it occurred in the blood and or lung, and if so at what acute time points; additionally, we examined the profile of immune cells in liver and splenic tissue 6hr after injury to investigate the sub-acute distal organ effects of PBLI. 


\section{Methods}

Animals and Licence

Sprague-Dawley female rats $(200-280 \mathrm{~g})$ were purchased from Charles River (Kent, UK) under Home Office licence. Food and water were supplied ad libitum. U.K. Home Office guidelines for animal welfare were strictly observed. This study was performed under full institutional and departmental licence with ethic committee and Home Office approval. Euthanasia was performed under license by overdose intraperitoneal (I.P.) injection of pentobarbitone.

\section{Isolated PBLI Model}

Blunt thoracic trauma was induced using a compressed air driven shock tube (Figure S1) as detailed in the supplementary. A purpose-built subject support (Figure S2) bolted onto the outlet flange of the shock tube was used to expose only the thorax to a single focal shock wave. No part of the rat was inside the shock tube at any time. In this study a burst pressure of 14 bar was utilised delivering a peak pressure at the chest of $\sim 130 \mathrm{kPa}$. Polyethylene inserts enabled driver volume to be reduced to $10 \%$ of maximum; producing a short-duration shock wave (Figure S3). Full shock tube characterisation and rig details are included in the supplementary.

\section{Procedure and Physiological Measurements}

Rat physiology was recorded using a MouseOx system (Starr Life Sciences Corp, USA) in accordance with manufacturer's instructions. Rats were anaesthetized with I.P. injection of 60 $\mathrm{mg} / \mathrm{kg}$ ketamine and $0.20 \mathrm{mg} / \mathrm{kg}$ medetomidine and a single shock wave was applied to the chest. Shams did not receive a shock wave but were otherwise treated identically. After the procedure rats were injected with atipamezole I.P. to reverse sedation and were administered buprenorphine analgesia sub-cutaneously.

Following atipamezole injection animals regained consciousness in under 10 mins, with no difference in recovery time between sham and blasted rats. Physiological measurements were made $1 \mathrm{~min}$ and $5 \mathrm{~min}$ after anaesthesia, 1 min and 5 min after shock wave application, immediately after recovery and $3 \mathrm{hr}$ and $6 \mathrm{hr}$ thereafter.

\section{$\underline{\text { Tissue collection }}$}

Unless otherwise stated, centrifugations were performed at $4^{\circ} \mathrm{C}$ and media used throughout was Roswell Park Memorial Institute medium (RPMI) (Sigma-Aldrich) containing 10\% Fetal Bovine Serum (FBS) (Invitrogen, USA). After pentobarbitone overdose, blood was collected in citrated tubes on ice from the right femoral vein and centrifuged at $1300 \mathrm{~g}$ for 10 mins. Each sample was obtained from an individual subject, there were no repeat samplings of tissue or blood in this study. Plasma was collected and stored at $-80^{\circ} \mathrm{C}$ for further analysis. Whole lungs were lavaged twice using $3 \mathrm{~mL}$ of ice cold RPMI each with a 30 second pause before collection, in order to gain a representative sample of the total lung environment, as performed previously ${ }^{23}$. Volume and duration of lavage were standardised across all samples to ensure consistent Broncho-alveolar lavage fluid (BALF) concentrations and lung tissue cytokine measurements. BALF was centrifuged at $800 \mathrm{~g}$ for $5 \mathrm{mins}$, supernatant was stored at $-80^{\circ} \mathrm{C}$ and cells were resuspended on ice. For FCM tissue analysis: right inferior lung lobes, superior caudate liver lobes and spleen were collected in media on ice.

\section{Tissue processing}


Lung and liver lobes were cut by scissor into smaller fragments and suspended in media containing tissue digestion enzymes; DNAse I 5mg/mL, Collagenase D 30mg/mL and Dispase II $5 \mathrm{mg} / \mathrm{mL}$ (all from Roche, Switzerland). Tissue was incubated in digestion buffer in a water bath with shaking at $37^{\circ} \mathrm{C}$ for 30 minutes. After, liver cells were resuspended in $36 \%$ Percoll (Sigma-Aldrich) ${ }^{31,23}$ and centrifuged for $10 \mathrm{mins}$ at $500 \mathrm{~g}$ without break to separate leukocytes from fibrous tissue. Spleen was cut into smaller fragments but not subjected to enzymatic digestion. All tissues were strained using a $40 \mu \mathrm{M}$ nylon mesh (Fisher Scientific, USA). Red blood cells were lysed using Ammonium-Chloride-Potassium buffer as previously described ${ }^{23}$. Cell pellets were resuspended and viable cells counted using Trypan blue staining solution on a haemocytometer (Nikon, Tokyo Japan). Liver (Right Lateral Lobe) and lung (left lobe) were harvested and fixed for $24 \mathrm{hrs}$ in $10 \%$ Buffered Formalin. Paraffin-embedded sections (4 $\mu \mathrm{m})$ were stained with hematoxylin and eosin (H\&E). Images of the slides were captured using a light microscope (Leica, Germany). Cytospins were performed on glass covered slips stained with Wright-Geimsa stain (Sigma-Aldrich).

\section{Flow cytometry}

Flow cytometry was conducted based on staining protocols and methods reported previously ${ }^{23}$. Briefly, cells were stained with antibodies as detailed in Table S1; washed and stained with Live/Dead dye (eBioscience, USA) in PBS, before blocking with anti-CD32 and staining with antibodies in buffer containing PBS, Bovine Serum Albumin (1\%) (BSA) and Sodium Azide $(0.1 \%)$. Cells were stained with antibodies at concentrations stated in Table S1, incubated at $4^{\circ} \mathrm{C}$ for $30 \mathrm{mins}$ then washed and fixed (BD Cell Fix) before analysis using a multi-parameter flow cytometer (Fortessa LSR BD Biosciences, USA). Compensation was performed using fluorescent beads (OneComp eBeads, eBioscience).

\section{$\underline{\text { ELISA }}$}

BALF was thawed and analysed using a multiplex ELISA (MesoScaleDiscovery Maryland, USA) according to the manufacturer's instructions for IL- 6 , TNF- $\alpha$, IL-1 $\beta$, IFN-y and CXCL1. BALF Albumin and MCP-1 were both analysed by ELISA (Bethly Laboratories, USA and eBioscience respectively) according to manufacturer's instructions. In both instances, ELISA plates were allowed to develop and absorbance measured on a spectrophotometer (Tecan, Switzerland).

\section{Data \& Statistics}

In this study, a total of 39 rats were used across the sham and blast groups (Table 1). Where duplicate measures were taken, their means were first calculated and then included as a single measurement in further analysis (technical replicate); all data were collected from 2-3 separate individual experiments (biological replicate) and - unless otherwise stated - expressed as median $\pm 25 \%$ and $75 \%$ quartiles. Flow cytometric data were analysed using FlowJo v7.6.5 (Tree Star Inc, USA). Unless otherwise stated, statistical data analysed using a non-parametric Mann Whitney t-test in GraphPad Prism v5 (San Diego, USA), ${ }^{*} p<0.05,{ }^{* *} p<0.01$. Except for physiological data, individual animals were assayed for each time point. 


\section{Results}

Physiology

Subject survival was $100 \%$. As shown in Figure 1, rats subjected to a single shock wave experienced a transient bradycardia at $1 \mathrm{~min}$ (Figure 1A) $(258 \mathrm{bpm} \pm 10.30, \mathrm{p}<0.05)$ which had returned to sham levels by $5 \mathrm{~min}$. Rats recovered oxygenation (Figure 1B) by $5 \mathrm{mins}$ after PBLI and showed a mildly increased respiratory rate (Figure 1C) compared to shams throughout the study period $(\mathrm{p}>0.05)$.

\section{Pulmonary barotrauma and inflammation}

Histological hallmarks of pulmonary barotrauma were observed including free erythrocytes as a result of alveolar haemorrhage together with evidence of neutrophil and monocyte cell infiltration into the tissue (Figure 2A,B). There was no evidence of abdominal trauma in subjects with PBLI by liver histology (data not shown). To assess whether an inflammatory response had occurred in the lung and to support the validity of the PBLI initiated, BALF proteins were measured. Rises were observed in CXCL-1, IL-6 and TNF- $\alpha$ in the BALF at $3 \mathrm{hr}$ $(p>0.05)$ (Table 2$)$. We did not detect any significant increases in IFN- $\gamma$ or IL-1 $\beta$ cytokines in the BALF or plasma; we observed a three-fold and two-fold increase in plasma high mobility group box 1 protein (HMGB1) and Heat-shock protein 70 (HSP70) respectively at $6 \mathrm{hrs}(\mathrm{p}=0.2)$ (data not shown).

\section{Cellular immune response}

An increase in circulating neutrophils was observed in rats with PBLI (Figure 3A). Compared to shams, at $1 \mathrm{hr}$ this increase was three-fold $(\mathrm{p}<0.01)$ rising to almost five-fold $(\mathrm{p}<0.05)$ by 6hr. Likewise significant increases were seen in CD43Lo/His48Hi monocytes in the blood at all time points (Figure 3A); additionally, we saw a non-significant rise in total circulating leukocytes across the time course in rats with PBLI. This was most pronounced at $1 \mathrm{hr}(\mathrm{p}<0.01)$ (as illustrated by representative FCM plots in Figure 3B) and remained raised at $3 \mathrm{hr}(\mathrm{p}<0.05)$, beginning to subside by $6 \mathrm{hr}(\mathrm{p}<0.01)$. No significant differences in CD43Hi/His48Int-Lo monocytes, NK, B or T Cells were observed in the blood at any time point following PBLI (Table 3); though we did observe a gradual recovery in the number of circulating lymphocytes by $6 \mathrm{hr}$.

A marked increase in neutrophils in the lung was observed following PBLI (Figure 4A). This increase was three-fold at $1 \mathrm{hr}(\mathrm{p}<0.01)$ as illustrated in Figure $4 \mathrm{~B}$ and two-fold at $3 \mathrm{hr}(\mathrm{p}<0.05)$ as compared to levels in sham controls at each of these time points. By $6 \mathrm{hr}$ it had almost returned to sham levels. Additionally, significant increases were seen in CD43Lo/His48Hi monocyte-macrophages (Figure 4A) which were six-fold higher at $1 \mathrm{hr}(\mathrm{p}<0.01)$ and two-folder higher at $3 \mathrm{hr}(\mathrm{p}<0.05)$ before subsiding to levels comparable to sham by $6 \mathrm{hr}$. No significant differences were found in CD43Hi/His48Int-Lo monocyte-macrophages, NK, B or T Cells throughout the time course (Table 3). A significant increase in BALF neutrophils was seen at all time points post-injury, peaking at $3 \mathrm{hr}$ (Figure 5A). We examined whether any delayed changes in BALF monocyte-macrophages occurred at 3 or $6 \mathrm{hr}$; a significant increase in CD43Lo/His48Hi monocyte-macrophages was seen at 3hr (Figure 5B) but neither monocytemacrophage subset was raised at $6 \mathrm{hr}$ (Figure 5B). A significant increase was also observed in BALF MCP-1 concentration at $3 \mathrm{hr}(\mathrm{p}<0.05)$ and $6 \mathrm{hr}(\mathrm{p}<0.01)$ (Figure 5C). 


\section{Distal inflammation}

No significant differences were seen in immune cell proportions in the liver at $6 \mathrm{hr}$ (Figure 6A). However, we observed a trend towards lower neutrophils and NK Cells, and higher CD43Lo/His48Hi monocyte-macrophages and B Cells $(\mathrm{p}>0.05)$. In the spleen, significant increases in both monocyte-macrophage populations $(p<0.05)$ and decreases in CD4 T Cells was observed $(\mathrm{p}<0.05)$; no significant differences were seen in neutrophil, NK or B Cells. No significant difference was observed in absolute numbers of cells in the spleen between PBLI and sham (data not shown). 


\section{Discussion}

Model

The aim of this study was to discern the immune response to isolated PBLI - in the absence of other blast injury mechanisms or distal organ insult. In this study we utilised a compressed air driven shock tube and custom designed rig to induce PBLI through reproducible shock wave loading of the chest alone (Figure S2, S3 and Table S3) and not the head and abdomen. Notably, we measured the loading at the chest as well as shock tube outlet; a measure lacking from previous reports of PBLI ${ }^{32}$. Preliminary experiments established that loading the chest with $138 \mathrm{kPa}$ for $\sim 2 \mathrm{~ms}$ induced a consistently survivable injury. Female rats were used in this study, their immune cell biology is highly comparable to male rats, and demonstrates homology to murine and human immune systems - a prerequisite for further translational research.

\section{Hallmarks of pulmonary barotrauma}

PBLI is characterised by several features, including, histological and physiological changes in the cardiorespiratory system. A transient bradycardia (as observed in Figure 1) is frequently reportedly in PBLI and is due to a vagal nerve mediated reflex, which in the absence of further insult resolves rapidly ${ }^{7,8}$. We saw a modest but sustained increase in respiratory rate after PBLI, which may have been compensatory as a result of pulmonary damage and reduced gasexchange, thereby maintaining peripheral oxygenation in subjects ${ }^{33}$ throughout the study period. PBLI causes damage to lung tissue that promotes cellular infiltration, through the destructive effects of stress and shear waves at air-fluid tissue boundaries. In PBLI, studies have shown neutrophil infiltration histologically or by assaying activation markers such as MPO in BALF or lung homogenates 9-12,14,18,19,34. Our histological data showed marked cellular infiltration and free erythrocytes due to alveolar haemorrhage consistent with previous human and rodent reports ${ }^{11,35}$. Furthermore and in line with previous studies ${ }^{18,36}$, we observed increased BALF levels of CXCL-1, IL-6, TNF- $\alpha$ and albumin - an indicator of endothelial and epithelial barrier damage. Collectively these data support the validity of the injury generated in this system resulting in PBLI.

\section{Cellular inflammatory response}

This study is the first to directly enumerate7 immune cells using FCM in a rodent model of PBLI. An acute cellular inflammation was observed driven by neutrophils and classical monocytes in the blood and lung, together with increases in BALF neutrophils and monocytemacrophages.

\section{Neutrophils}

PBLI is known to elicit mobilisation of neutrophils from the bone marrow into the blood ${ }^{9,11,12}$ and promote their activation ${ }^{19,37}$. We saw significant increases in neutrophils in the blood across all time points, which may in part be driven by circulating chemokines and complement products previously reported to be elevated in PBLI ${ }^{12,19,36,37}$. Additionally, we observed a rapid increase in neutrophils in the lung at 1 and $3 \mathrm{hr}$, returning to baseline by $6 \mathrm{hr}$. Blast damage to blood vessels leads to their rupture and leakage of vascular contents into the parenchyma as seen in this study; it has been shown that neutrophils can attach to these red blood cells in haemorrhagic foci ${ }^{38}$.

\section{Monocyte-Macrophages}


Understanding of the role of other immune cells in PBLI is limited, with few studies examining the monocyte response. Those which have show isolated monocytes $4 \mathrm{hr}$ post-injury express higher levels of CCR2 mRNA compared to sham, and exhibit reduced migratory potential exvivo to chemoattractants ${ }^{18}$. Another study by the same authors, using a combined model of PBLI and haemorrhage showed reduced pro-inflammatory cytokine production from peripheral blood mononuclear cells (PBMCs) ex-vivo after combined insult at $20 \mathrm{hr}{ }^{15}$, whilst another study at $2 \mathrm{hr}$ showed increased cytokine production from peripheral blood mononuclear cells ${ }^{39}$.

To determine the still unclear nature of the monocyte response to PBLI in vivo, we used FCM to examine changes in the two circulating rat monocyte populations. To the best of our knowledge, we report for the first time a significant and sustained response of CD43Lo/His48Hi (classical) circulating monocytes to PBLI in the rat. These cells were raised as early as $1 \mathrm{hr}$ after insult and only began to subside by $6 \mathrm{hr}$. Interestingly, this increase was not seen amongst the CD43Hi/His48Int-Lo (non-classical) monocyte subset. We found increases in plasma MCP-1 in PBLI rats compared to shams at all time-points, however this only reached significance at $6 \mathrm{hr}$ (data not shown). In a model of primary blast limb injury, CD43Lo but not $\mathrm{CD} 43 \mathrm{Hi}$ monocytes were raised in the blood of rats subjected to prolonged duration blast waves 40.

A study of PBLI in mice suggested increases in BALF mononuclear cells as evidence for monocyte migration to the lung ${ }^{18}$. Alongside marked changes in circulating cells, we found a rapid and significant increase in CD43Lo/His48Hi monocyte-macrophages at $1 \mathrm{hr}$ in the lung compared to shams (Figure 4A, B), which had all but subsided by 6hr. This increase could be in part due to an accelerated recruitment by cytokines and chemokines such as CINC-1, MIP2 and enhanced ICAM-1 expression ${ }^{18,34,36,37}$ or damage products ${ }^{41}$, which we found raised in the plasma at $6 \mathrm{hr}$ of PBLI rats (data not shown). There was a significant increase in CD43Lo/His48Hi monocyte-macrophages at $3 \mathrm{hr}$ in the BALF supporting our correlate findings in the lung, together with significant increases at 3 and $6 \mathrm{hr}$ in the monocyte-macrophage chemoattractant MCP-1.

A study of PBLI in mice found no ameliorating effect of neutrophil depletion on acute lung injury and suggested monocytes (without subset discrimination) - which were raised in the blood - may be implicated in PBLI pathogenesis ${ }^{37}$. The elevation of CD43Lo monocytes in the blood and CD43Lo monocyte-macrophages in the lung and BALF seen in this study suggest they - like their murine Ly6+ equivalents - may play key effector rolls in responding to sterile as well as infectious inflammatory stimuli; indeed CD43Lo monocyte-macrophages have been reported in significantly increased numbers in the lung at 3 and 24hr in LPS-induced pulmonary inflammation ${ }^{23}$ and participate from the luminal side of the alveolar-capillary boundary as well as from within the parenchyma during lung allograft rejection ${ }^{42}$.

Other immune cells

Because of the lack of data on other immune cell types in PBLI, and evidence to suggest NK Cell ${ }^{43}$, B Cell ${ }^{44}, \mathrm{CD} 4+{ }^{45}$ and CD8+ ${ }^{46} \mathrm{~T}$ Cell involvement in trauma, we examined their changes in the circulation and lung in our model. There were no significant changes in the blood or lungs of these cells, supporting the view that PBLI releases damage mediators with specific- rather than pan-immune cell effects. Notably, these data highlight the importance of enumerating individual immune cell populations in blast injury studies; as lymphocytes 
predominate the circulating immune cell pool in rats ${ }^{23}$, assaying of total leukocytes numbers in the blood may not always rise significantly, even in the presence of significant circulating neutrophil or monocyte responses. Moreover, direct enumeration guards against misinterpretation of inflammation assays such as MPO - which is highly expressed by classical monocytes ${ }^{47}$ as well as neutrophils.

\section{Distal organ immune cells}

Evidence suggests distal organs may undergo delayed inflammatory changes following PBLI. Hepatic Kupffer cells are thought to become primed to release pro-inflammatory cytokines shortly after PBLI ${ }^{36}$. In a combined model of PBLI and femoral fracture, significant increases in lung and hepatic neutrophil infiltration were observed, peaking at $6 \mathrm{hr}{ }^{48}$. In rodent models of PBLI, splenic immune cells demonstrate supressed cytokine release ${ }^{30}$ which may be responsible for diminished survival following a septic 'second-hit' ${ }^{39}$. Yet, another study of PBLI found no effect on splenocyte cytokine release unless in the combined presence of neutrophil depletion ${ }^{37}$, suggesting a neutrophil specific role for splenic suppression.

In light of these varied and conflicting findings we sought to characterise in vivo the respective proportions of immune cells in the liver and spleen 6hr post-PBLI (Figure 6). In the liver we saw no significant changes in immune cells. In the spleen we saw significant increases in the proportion of $\mathrm{CD} 43 \mathrm{Lo} / \mathrm{His} 48 \mathrm{Hi}$ and $\mathrm{CD} 43 \mathrm{Hi} / \mathrm{His} 48 \mathrm{Int}-\mathrm{Lo}$ monocyte-macrophages, and significant decreases in $\mathrm{CD} 3+\mathrm{CD} 4+\mathrm{T}$ cells. Collectively these data demonstrate for the first time the immune cell environment of two major distal organs in PBLI. This splenic data is timely given recent studies in mice show the spleen can directly give rise to Ly-6C+ monocytes (analogous to CD43Lo rat monocytes) that respond to sterile inflammation ${ }^{49}$. Further understanding of the contribution of different tissues and organs to the immune response in PBLI is needed.

\section{Clinical implications and limitations}

Blast exposed patients may present with myriad clinical injuries or symptoms, many of which could appear benign and thereby complicate simple and rapid triage during mass-casualty events. Anecdotal surrogates for PBLI such as tympanic membrane perforation are not supported by evidence ${ }^{50}$. It is important to identify patients that have suffered PBLI even if the injury doesn't appear immediately life threatening. This study offers evidence to suggest CD43 Lo classical monocytes - in addition to neutrophils - can be detected in the blood or BALF acutely after PBLI; and could offer clinicians an additional triage tool to identify those at potential risk of deleterious systemic immune activation or in need of further monitoring. Importantly, the immune response in a real-world clinical environment will be additionally impacted by interacting blast injury mechanisms and damage to distal organs, as well as the immune response to therapeutic intervention such as blood transfusion. A limitation of this study is that it does not examine quantitatively whether circulating or BALF immune cells correlate with injury severity; this should be a focus of further research.

\section{Conclusion}

In summary, this study shows that isolated PBLI leads to a rapid increase in circulating neutrophils and - for the first time - CD43Lo/His48Hi monocytes. These cells are also elevated in the lung at 1 and $3 \mathrm{hrs}$ but return to baseline levels by 6hrs. We show specific monocyte- 
macrophage immune cell changes in the spleen but not liver $6 \mathrm{hr}$ after injury. The methodology employed in this study adds clarity to the varied roles played by immune cells in PBLI across several tissues. Neutrophils and classical monocytes may serve as tools in translation studies to assess blast injured subjects or patients, including those considered susceptible to systemic immune activation or 'second-hits' such as infection.

Word Count: 3820

\section{Acknowledgments}

This work was conducted under the auspices of the Royal British Legion Centre for Blast Injury Studies at Imperial College London. The authors would like to acknowledge the financial support of the Royal British Legion; Mr Satpal Sangha for their technical support; Ms Lorraine Lawrence for their histological assistance, Dr Miland Joshi for their statistical assistance and the Flow Cytometry facility at South Kensington Campus for their expert assistance and advice.

\section{Statement of authorship}

$\mathrm{ABV}$ and SR designed the research; ABV, AS, TE, HA conducted the experiments; HA, WM, $\mathrm{AB}, \mathrm{SR}$ offered technical experimental guidance and assistance; ABV, TE, HA, AS analysed the data; ABV and SR wrote the paper with input from AS, TE, HA, WM, AB. 
Figure 1 Physiological effects of shock wave induced PBLI

\section{Legend}

Physiological measurements after sham (-) or PBLI (------). Rats were anesthetized and subjected to a single shock wave or sham procedure. An infra-red neck collar Sensor was used to measure heart rate (A), arterial oxygen saturation (B) and respiratory rate (C). Recordings were taken at $1 \mathrm{~min}$ and $5 \mathrm{~min}$ after induction of anaesthesia, $1 \mathrm{~min}$ and $5 \mathrm{~min}$ after PBLI, after recovery when rats were awake, and $3 \mathrm{hr}$ and $6 \mathrm{hr}$ thereafter. Peri-anaesthesia $\mathrm{n}=9-19$; at $3 \mathrm{hrs}$ $\mathrm{n}=6-11$; at $6 \mathrm{hrs} \mathrm{n}=3$ from 2-3 independent experiments presented mean $\pm \mathrm{SEM}$ using unpaired t-test where $* \mathrm{p}<0.05$.

Figure 2 Histological changes in the lung after injury

Legend

Histological imaging of lungs after sham or PBLI. Left lung lobes were fixed in formaldehyde, embedded in wax, cut and stained with H\&E. Images are representative obtained from a light microscope at 10X (A), 40X or 100X (B) magnification. Images are representative.

Figure 3 Neutrophils and CD43Lo/His48Hi Monocytes are elevated in the blood after PBLI

Legend

Total cells, neutrophils and $\mathrm{CD} 43 \mathrm{Lo} / \mathrm{His} 48 \mathrm{Hi}$ monocyte levels (A), representative flow cytometry (FCM) images (B) in the blood at 1, 3 and $6 \mathrm{hr}$ after sham (-) or PBLI (+). Cells were distinguished and enumerated by 9-colour FCM. Data are: at $1 \mathrm{hr} n=7-8$, at $3 \mathrm{hr} \mathrm{n}=6-7$, at $6 \mathrm{hr}$ $\mathrm{n}=5$, in each group from 2-3 independent experiments presented as median $\pm 25^{\text {th }}$ and $75^{\text {th }}$ percentile where $* \mathrm{p}<0.05,{ }^{* *} \mathrm{p}<0.01$.

Figure 4 Rapid recruitment of Neutrophils and CD43Lo/His48Hi Monocyte-Macrophages to the lung

Legend

Fold changes in total neutrophils and CD43Lo/His48Hi monocyte-macrophages (A), representative flow cytometry (FCM) images (B) in the lung at 1, 3 and $6 \mathrm{hr}$ all compared to time point specific shams. Cells were distinguished and enumerated by 9 -colour FCM. Data are: at $1 \mathrm{hr} \mathrm{n}=7-8$, at $3 \mathrm{hr} \mathrm{n}=6-7$, at $6 \mathrm{hr} \mathrm{n}=5$, in each group from 2-3 independent experiments, presented as median fold change over sham-specific time point group \pm 25 th and 75 th percentile where $* \mathrm{p}<0.05,{ }^{*} \mathrm{p}<0.01$.

\section{$\underline{\text { Figure } 5 \text { Cellular BALF changes after PBLI }}$}

\section{Legend}

Total neutrophils and neutrophils as percentage of total cells (A) in BALF at 1, 3 and 6hr; total CD43Lo/His48Hi monocyte-macrophages (B) 3 and 6hr; concentration of MCP-1 in the BALF at 1, 3 and $6 \mathrm{hr}(\mathrm{C})$ after sham (-) or PBLI (+). Cells were distinguished and enumerated by FCM. Cellular data are: total cells in each group at $1 \mathrm{hr} n=5,3 \mathrm{hr} n=6-7,6 \mathrm{hr} n=5-6$; neutrophils in each group at $1 \mathrm{hr} n=7-8$, at $3 \mathrm{hr} n=6-7$, at $6 \mathrm{hr} n=5-6$; CD43Lo and CD43Hi monocytes in each group at $3 \mathrm{hr} n=6$, at $6 \mathrm{hrs} n=2-3$. MCP-1 ELISA data in each group are: $1 \mathrm{hr} n=3-5,3 \mathrm{hr}$ $\mathrm{n}=5,6 \mathrm{hr} \mathrm{n}=5$ from $2-3$ independent experiments run in duplicate. All data presented as median \pm 25 th and 75 th percentile where $* p<0.05, * * p<0.01$. Summary error measures are not presented where $\mathrm{n}<=3$. 
$\underline{\text { Figure } 6} \underline{\text { Immune cells in distal tissues at } 6 \mathrm{hr}}$

Legend

Proportions of neutrophils, CD43Lo/His48Hi monocyte-macrophages, NK, B and T cells of total cells in Liver (A) and Spleen (B) at $6 \mathrm{hr}$ after sham (-) or PBLI (+). Cells were distinguished and enumerated by FCM. Liver data in each group are $n=5-6$; spleen data in each group are $n=4-6$; both from 2-3 independent experiments presented as median \pm 25 th and 75 th percentile where $* \mathrm{p}<0.05, * * \mathrm{p}<0.01$.

Table 1: Study groups and subjects

Legend

Subjects included in this study at each time point.

Table 2 Pulmonary inflammatory changes in the BALF

Legend

CXCL-1, IL-6 and TNF- $\alpha$ cytokines and albumin in the BALF at 1, 3 and $6 \mathrm{hr}$ after sham or PBLI. Multiplex ELISA data in each group: CXCL-1, IL-6 and TNF-a all $n=4$ in duplicate from 2-3 independent experiments at all time points; Albumin data in each group: at $1 \mathrm{hr} n=5$, $3 \mathrm{hr} \mathrm{n}=6-7,6 \mathrm{hr} \mathrm{n}=5-6$, all in duplicate from 2-3 independent experiments. Data presented as median \pm 25 th and 75 th percentile where $* p<0.05, * * p<0.01$.

Table 3 Immune cells in the blood and lung

Legend

CD43Hi/His48Lo monocyte-macrophages, NK, B and T cells at 1, 3 and 6hrs in the blood and lung. Data are: at $1 \mathrm{hr} n=7-8$, at $3 \mathrm{hr} n=6-7$, at $6 \mathrm{hr} n=5$, in each group from 2-3 independent experiments presented as median $\pm 25^{\text {th }}$ and $75^{\text {th }}$ percentile where ${ }^{*} p<0.05,{ }^{* *} p<0.01$. Lung data is shown as a ratio to time-specific sham groups. CD8 data were unobtainable in sufficient numbers at $6 \mathrm{hrs}$ and are not included. 


\section{REFERENCES}

1. Wolf SJ, Bebarta VS, Bonnett CJ, Pons PT, Cantrill SV. Blast injuries. Lancet. 2009;374:405-415.

2. Frykberg ER, Tepas JJ,3rd. Terrorist bombings. lessons learned from belfast to beirut. Ann Surg. 1988;208:569-576.

3. Aboudara M, Mahoney PF, Hicks B, Cuadrado D. Primary blast lung injury at a NATO role 3 hospital. J R Army Med Corps. 2014;160:161-166.

4. Aboudara M, Hicks B, Cuadrado D, Mahoney PF, Docekal J. Impact of primary blast lung injury during combat operations in afghanistan. Journal of the Royal Army Medical Corps. 2015.

5. Irwin RJ, Lerner MR, Bealer JF, Mantor PC, Brackett DJ, Tuggle DW. Shock after blast wave injury is caused by a vagally mediated reflex. J Trauma. 1999;47:105-110.

6. Seitz DH, Perl M, Mangold S, Neddermann A, Braumuller ST, Zhou S, Bachem MG, HuberLang MS, Knoferl MW. Pulmonary contusion induces alveolar type 2 epithelial cell apoptosis: Role of alveolar macrophages and neutrophils. Shock. 2008;30:537-544.

7. Sawdon M, Ohnishi M, Watkins PE, Kirkman E. The effects of primary thoracic blast injury and morphine on the response to haemorrhage in the anaesthetised rat. Exp Physiol. 2002;87:683-689.

8. Ohnishi M, Kirkman E, Guy RJ, Watkins PE. Reflex nature of the cardiorespiratory response to primary thoracic blast injury in the anaesthetised rat. Exp Physiol. 2001;86:357-364.

9. van Wessem KJP, Hennus MP, van Wagenberg L, Koenderman L, Leenen LPH. Mechanical ventilation increases the inflammatory response induced by lung contusion. J Surg Res. 2013;183:377-384.

10. Liener UC, Knoferl MW, Strater J, Barth TF, Pauser EM, Nussler AK, Kinzl L, Bruckner UB, Gebhard F. Induction of apoptosis following blunt chest trauma. Shock. 2003;20:511-516.

11. Knoferl MW, Liener UC, Seitz DH, Perl M, Bruckner UB, Kinzl L, Gebhard F. Cardiopulmonary, histological, and inflammatory alterations after lung contusion in a novel mouse model of blunt chest trauma. Shock. 2003;19:519-525.

12. Flierl MA, Perl M, Rittirsch D, Bartl C, Schreiber H, Fleig V, Schlaf G, Liener U, Brueckner UB, Gebhard $\mathrm{F}$ et al. . The role of $\mathrm{C} 5 \mathrm{a}$ in the innate immune response after experimental blunt chest trauma. Shock. 2008;29:25-31. 
13. Satoh Y, Sato S, Saitoh D, Tokuno S, Hatano B, Shimokawaji T, Kobayashi H, Takishima K. Pulmonary blast injury in mice: A novel model for studying blast injury in the laboratory using laser-induced stress waves. Lasers Surg Med. 2010;42:313-318.

14. Perl M, Hohmann C, Denk S, Kellermann P, Lu D, Braumuller S, Bachem MG, Thomas J, Knoferl MW, Ayala A et al. . Role of activated neutrophils in chest trauma-induced septic acute lung injury. Shock. 2012;38:98-106.

15. Seitz DH, Perl M, Liener UC, Tauchmann B, Braumuller ST, Bruckner UB, Gebhard F, Knoferl MW. Inflammatory alterations in a novel combination model of blunt chest trauma and hemorrhagic shock. J Trauma. 2011;70:189-196.

16. Garner J, Watts S, Parry C, Bird J, Cooper G, Kirkman E. Prolonged permissive hypotensive resuscitation is associated with poor outcome in primary blast injury with controlled hemorrhage. Ann Surg. 2010;251:1131-1139.

17. Garner JP, Watts S, Parry C, Bird J, Kirkman E. Development of a large animal model for investigating resuscitation after blast and hemorrhage. World J Surg. 2009;33:2194-2202.

18. Seitz DH, Niesler U, Palmer A, Sulger M, Braumuller ST, Perl M, Gebhard F, Knoferl MW. Blunt chest trauma induces mediator-dependent monocyte migration to the lung. Crit Care Med. 2010;38:1852-1859.

19. Gorbunov NV, McFaul SJ, Van Albert S, Morrissette C, Zaucha GM, Nath J. Assessment of inflammatory response and sequestration of blood iron transferrin complexes in a rat model of lung injury resulting from exposure to low-frequency shock waves. Crit Care Med. 2004;32:1028-1034.

20. Passlick B, Flieger D, Ziegler-Heitbrock H. Identification and characterization of a novel monocyte subpopulation in human peripheral blood. Blood. 1989;74:2527-2534.

21. Tsou CL, Peters W, Si Y, Slaymaker S, Aslanian AM, Weisberg SP, Mack M, Charo IF. Critical roles for CCR2 and MCP-3 in monocyte mobilization from bone marrow and recruitment to inflammatory sites. J Clin Invest. 2007;117:902-909.

22. Serbina NV, Pamer EG. Monocyte emigration from bone marrow during bacterial infection requires signals mediated by chemokine receptor CCR2. Nat Immunol. 2006;7:311-317.

23. Barnett-Vanes A, Sharrock A, Birrel M, Rankin SM. A single 9-colour flow cytometric method to characterise major leukocyte populations in the rat: Validation in a model of LPS-induced pulmonary inflammation. PLoS One. 11(1):e0142520. 2016. 
24. Lin SL, Castaño AP, Nowlin BT, Lupher ML, Duffield JS. Bone marrow Ly6Chigh monocytes are selectively recruited to injured kidney and differentiate into functionally distinct populations. The Journal of Immunology. 2009;183:6733-6743.

25. Dhaliwal K, Scholefield E, Ferenbach D, Gibbons M, Duffin R, Dorward DA, Morris AC, Humphries D, MacKinnon A, Wilkinson TS et al. . Monocytes control second-phase neutrophil emigration in established lipopolysaccharide-induced murine lung injury. Am J Respir Crit Care Med. 2012;186:514-524.

26. Scriba A, Schneider M, Grau V, van der Meide PH, Steiniger B. Rat monocytes up-regulate NKR-P1A and down-modulate CD4 and CD43 during activation in vivo: Monocyte subpopulations in normal and IFN-gamma-treated rats. Journal of Leukocyte Biology. 1997;62:741-752.

27. Lu R, Zhou X, Ji W, Luo Y, Yang G, Sun H, Ge L, Jiang T, Li Y. Dynamic changes of peripheral blood monocyte subsets after myocardial ischemia/reperfusion in rats. Xi Bao Yu Fen Zi Mian Yi Xue Za Zhi. 2014;30:131-134.

28. Ning J, Mo L, Zhao H, Lu K, Wang L, Lai X, Yang B, Zhao H, Sanders RD, Ma D. Transient regional hypothermia applied to a traumatic limb attenuates distant lung injury following blast limb trauma. Crit Care Med. 2014;42:e68-78.

29. Zhao H, Ning J, Duan J, Gu J, Yi B, Lu K, Mo L, Lai X, Hennah L, Ma D. Regional traumatic limb hypothermia attenuates distant hepatic and renal injury following blast limb trauma in rats. J Trauma Acute Care Surg. 2014;77:464-470.

30. Knoferl MW, Liener UC, Perl M, Bruckner UB, Kinzl L, Gebhard F. Blunt chest trauma induces delayed splenic immunosuppression. Shock. 2004;22:51-56.

31. Hardy CL, Bhathal PS, Snibson KJ, Adams TE. Comparison of intrahepatic lymphocytes from normal and growth hormone transgenic mice with chronic hepatitis and liver cancer. Immunology. 1997;90:412-420.

32. Guy R, Watkins PE. Cardiopulmonary, histological and inflammatory alterations after lung contusion in a novel mouse model of blunt chest trauma. shock 19(6):519-525, 2003. Shock. 2004;21:190-1; author reply 191.

33. Grisk O, Exner J, Schmidt M, Honig A. Effects of acute hypoxia and hyperoxia on ventilation in spontaneously hypertensive and normotensive rat. $J$ Auton Nerv Syst. 1996;57:177-180.

34. Chavko M, Prusaczyk WK, McCarron RM. Lung injury and recovery after exposure to blast overpressure. J Trauma. 2006;61:933-942. 
35. Tsokos M, Paulsen F, Petri S, Madea B, Puschel K, Turk EE. Histologic, immunohistochemical, and ultrastructural findings in human blast lung injury. Am J Respir Crit Care Med. 2003;168:549-555.

36. Perl M, Gebhard F, Braumuller S, Tauchmann B, Bruckner UB, Kinzl L, Knoferl MW. The pulmonary and hepatic immune microenvironment and its contribution to the early systemic inflammation following blunt chest trauma. Crit Care Med. 2006;34:1152-1159.

37. Perl M, Kieninger M, Huber-Lang MS, Gross HJ, Bachem MG, Braumuller S, Gebhard F, Ayala A, Knoferl MW. Divergent effects of activated neutrophils on inflammation, kupffer cell/splenocyte activation, and lung injury following blunt chest trauma. Shock. 2012;37:210218.

38. Gorbunov NV, Asher LV, Ayyagari V, Atkins JL. Inflammatory leukocytes and iron turnover in experimental hemorrhagic lung trauma. Exp Mol Pathol. 2006;80:11-25.

39. Perl M, Gebhard F, Bruckner UB, Ayala A, Braumuller S, Buttner C, Kinzl L, Knoferl MW. Pulmonary contusion causes impairment of macrophage and lymphocyte immune functions and increases mortality associated with a subsequent septic challenge. Crit Care Med. 2005;33:1351-1358.

40. Eftaxiopoulou T, Barnett-Vanes A, Arora H, Macdonald W, Nguyen T, Itadani M, Sharrock A, Britzman D, Proud WG, Bull A et al. . Prolonged but not short duration blast waves elicit acute inflammation in a rodent model of primary blast limb trauma. Injury [In press]. 2015.

41. Liesz A, Dalpke A, Mracsko E, Antoine DJ, Roth S, Zhou W, Yang H, Na SY, Akhisaroglu $\mathrm{M}$, Fleming $\mathrm{T}$ et al. . DAMP signaling is a key pathway inducing immune modulation after brain injury $J$ Neurosci. 2015;35:583-598.

42. Blöcher S, Wilker S, Sucke J, Pfeil U, Dietrich H, Weimer R, Steger K, Kaufmann A, Hirschburger M, Plötz $\mathrm{C}$ et al. . Acute rejection of experimental lung allografts: Characterization of intravascular mononuclear leukocytes. 2007;124:98-108.

43. Kong X, Bai S, Chen X, Wei H, Jin W, Li M, Yan Y, Shi F. Alterations of natural killer cells in traumatic brain injury. 2014;30:903-912.

44. Richter M, Jodouin CA, Moher D, Barron P. Immunologic defects following trauma: A delay in immunoglobulin synthesis by cultured B cells following traumatic accidents but not elective surgery. J Trauma. 1990;30:590-596.

45. Gouel-ChÃ@ron A, Venet F, Allaouchiche B, Monneret G. CD4+ T-lymphocyte alterations in trauma patients. 2012;16:1-1. 
46. Aguilar MM, Battistella FD, Owings JT, Olson SA, MacColl K. Posttraumatic lymphocyte response: A comparison between peripheral blood $\mathrm{T}$ cells and tissue $\mathrm{T}$ cells. J Trauma. $1998 ; 45: 14-18$.

47. Swirski FK, Wildgruber M, Ueno T, Figueiredo JL, Panizzi P, Iwamoto Y, Zhang E, Stone JR, Rodriguez E, Chen JW et al. . Myeloperoxidase-rich ly-6C+ myeloid cells infiltrate allografts and contribute to an imaging signature of organ rejection in mice $J$ Clin Invest. 2010;120:2627-2634.

48. Neunaber C, Oestern S, Andruszkow H, Zeckey C, Mommsen P, Kutter D, Stöfen M, Krettek C, Hildebrand F. Cytokine productive capacity of alveolar macrophages and kupffer cells after femoral fracture and blunt chest trauma in a murine trauma model. Immunol Lett. 2013;152:159-166.

49. Robbins CS, Chudnovskiy A, Rauch PJ, Figueiredo JL, Iwamoto Y, Gorbatov R, Etzrodt M, Weber GF, Ueno T, van Rooijen N et al. . Extramedullary hematopoiesis generates ly6C(high) monocytes that infiltrate atherosclerotic lesions. Circulation. 2012;125:364-374.

50. Peters P. Primary blast injury: An intact tympanic membrane does not indicate the lack of a pulmonary blast injury. Mil Med. 2011;176:110-114. 
A

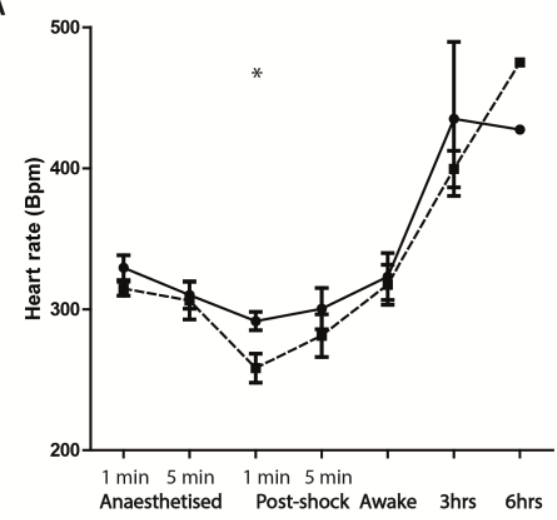

C

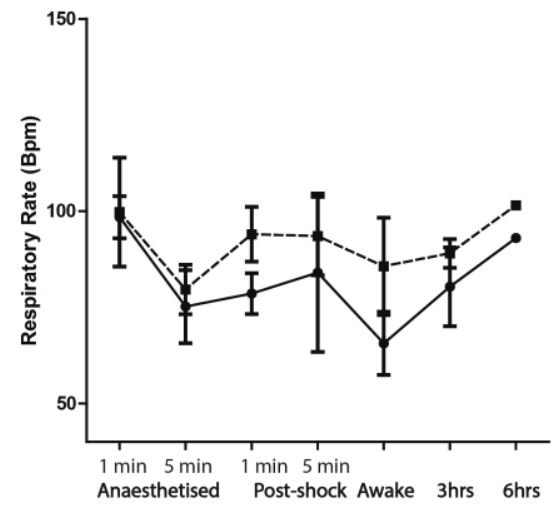

B

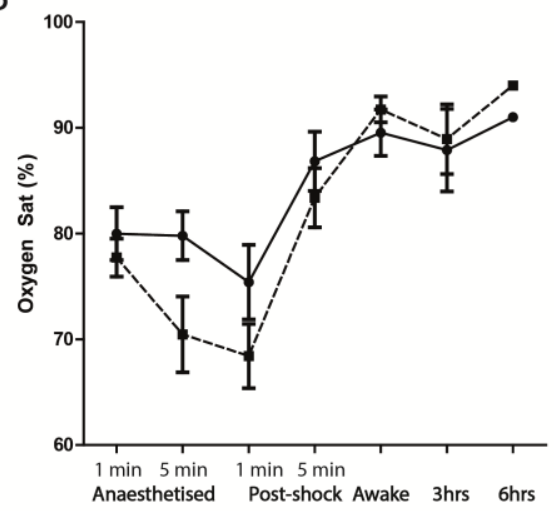

$\because$ Sham 
Figure 2
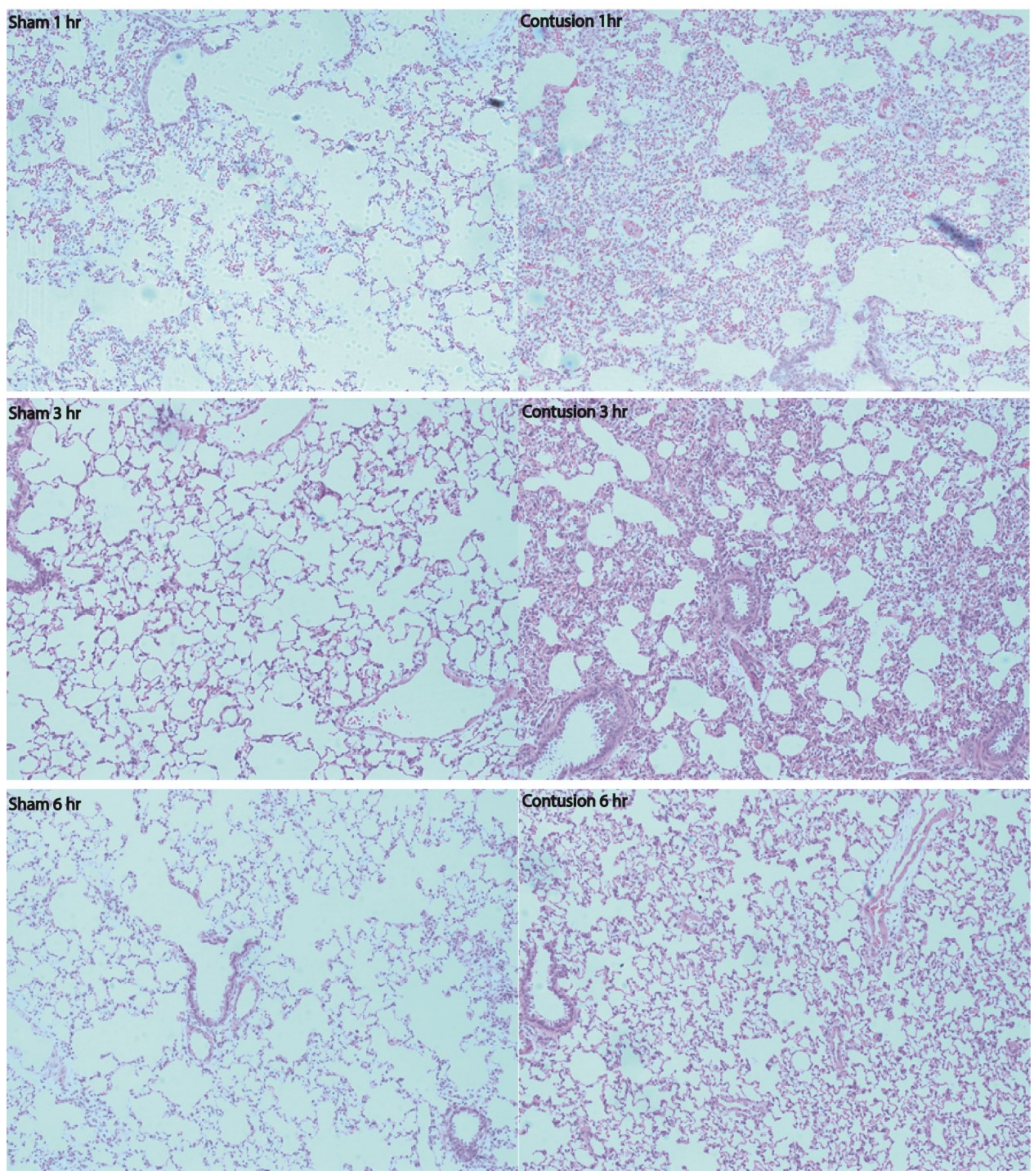
Figure $2 b$

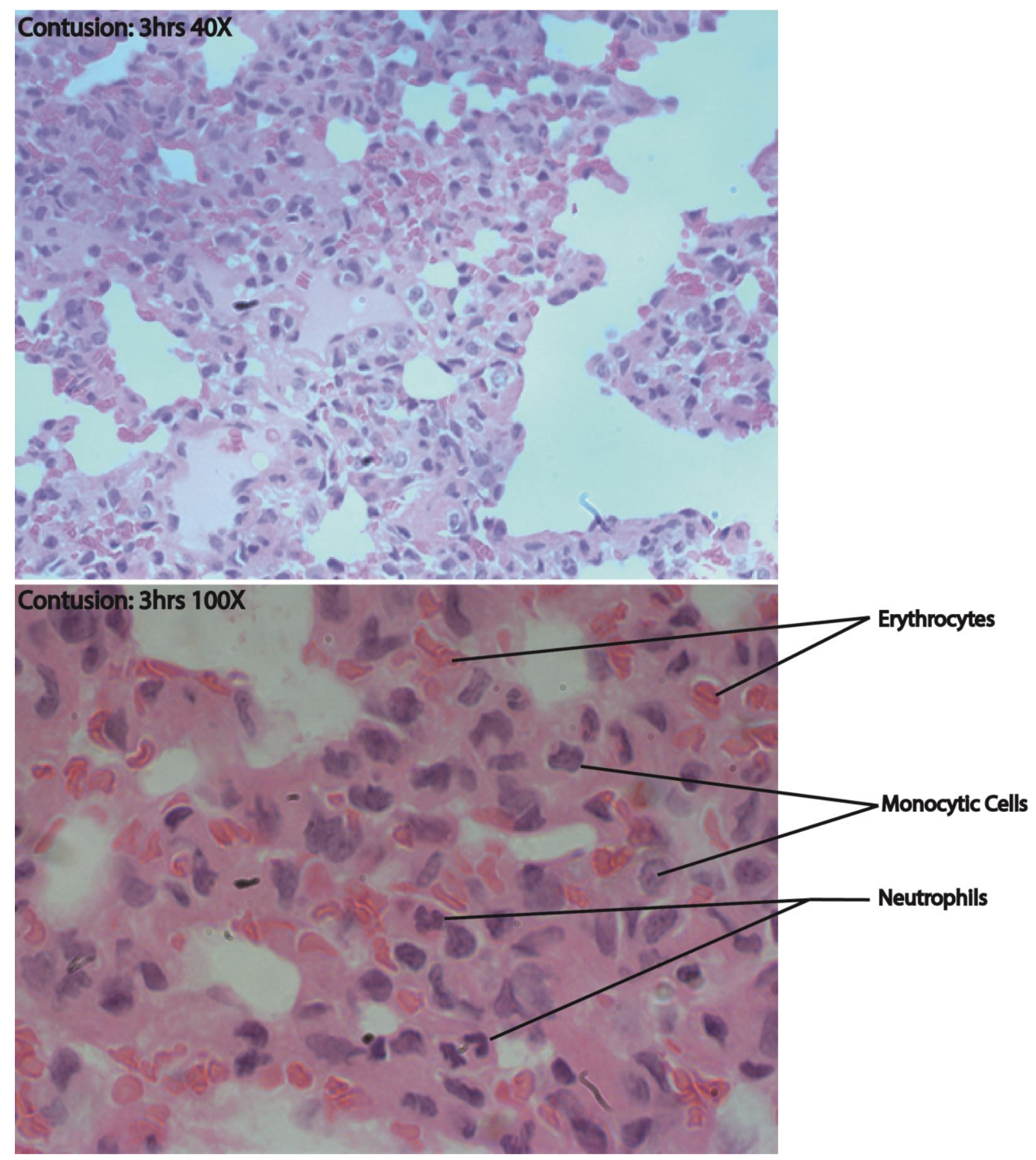


Figure 3

A
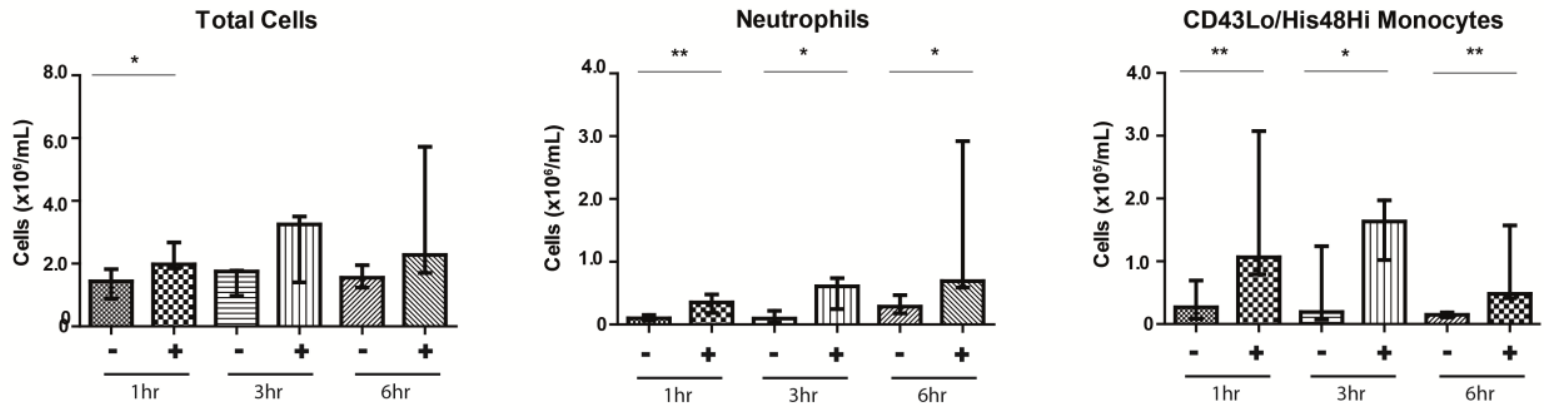

B

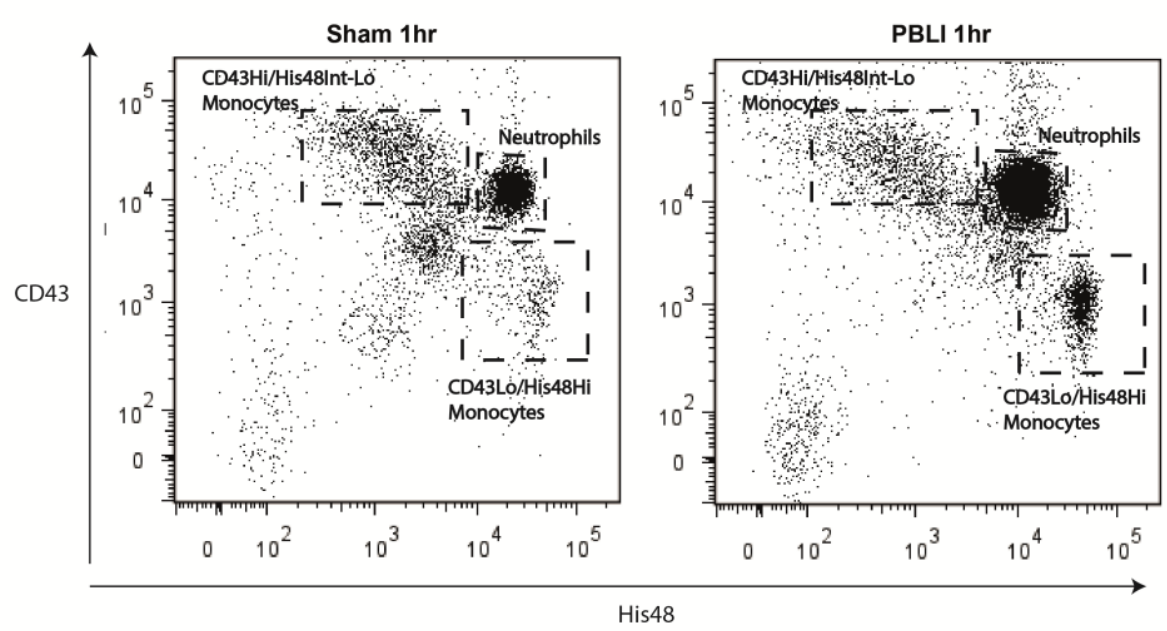


Figure 4

A

Neutrophils

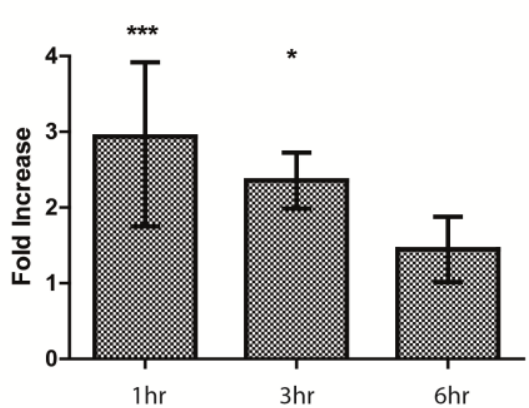

CD43Lo/His48Hi

Monocyte-Macrophages

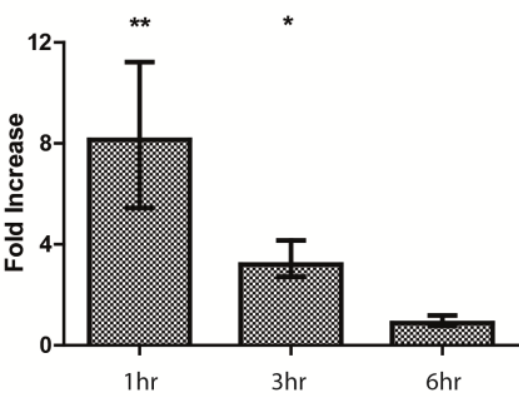

B
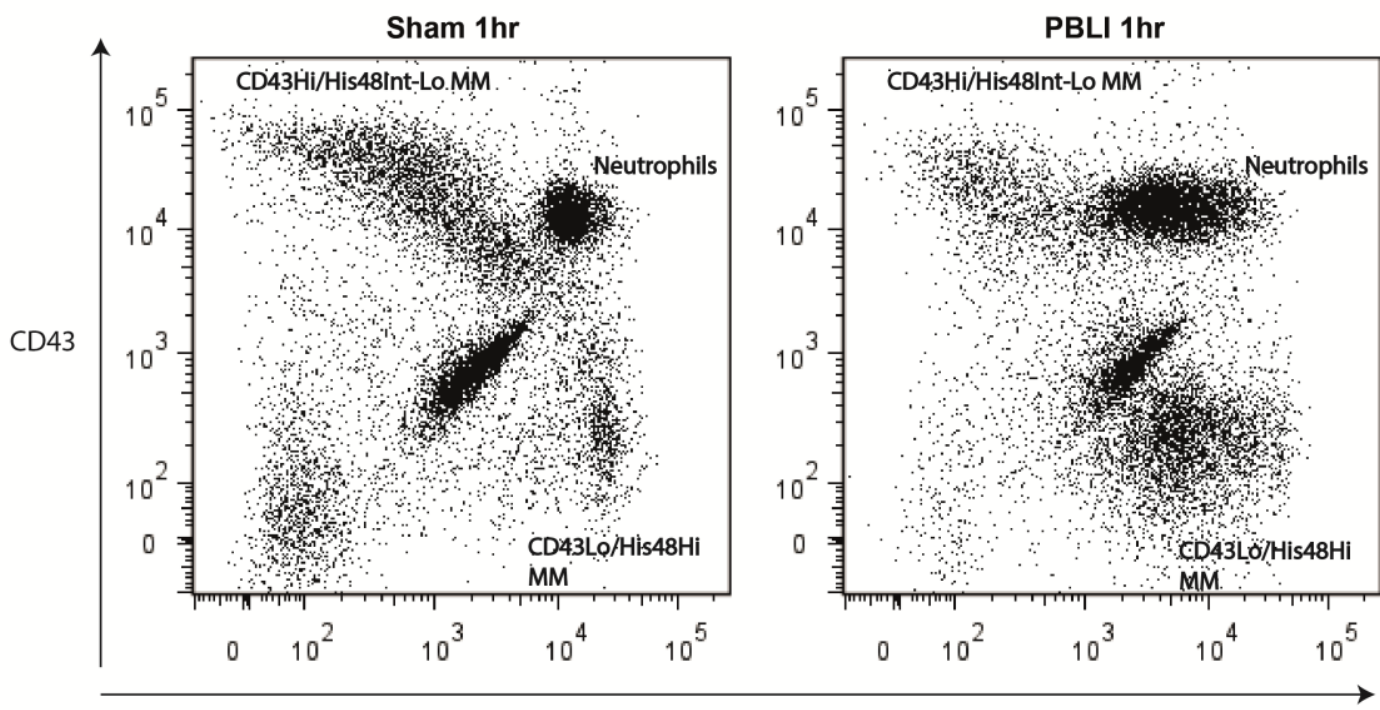

His48 
Figure 5

A

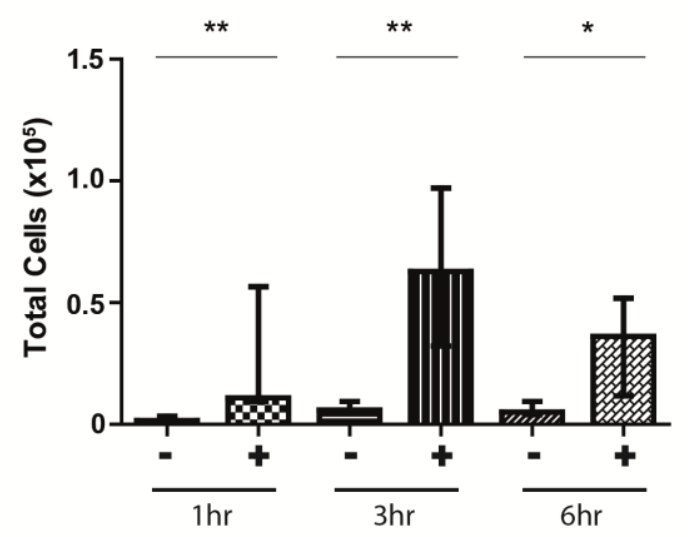

\section{Neutrophils}

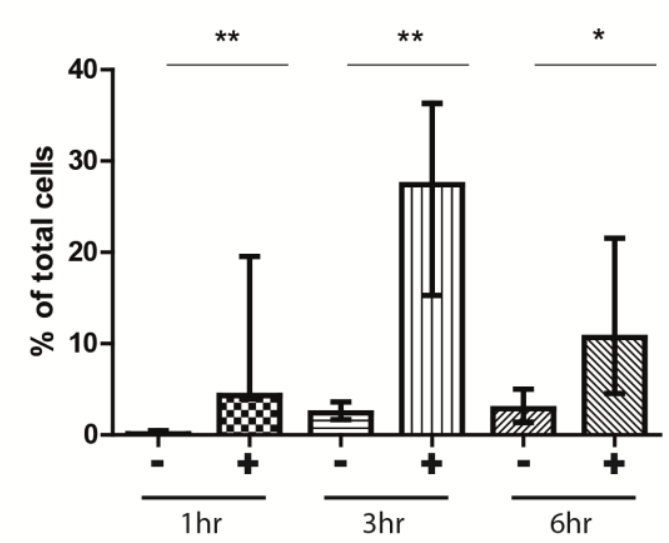

CD43Lo/His48

Monocyte-macrophages

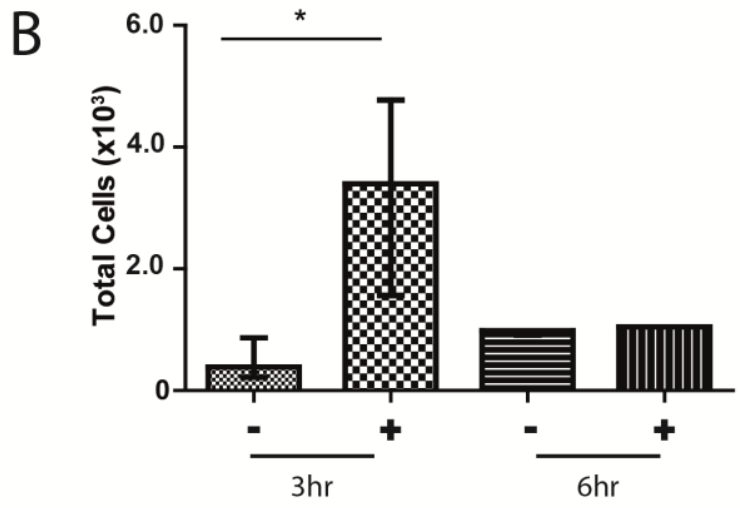

CD43Hi/His48Int-Lo

Monocyte-macrophages
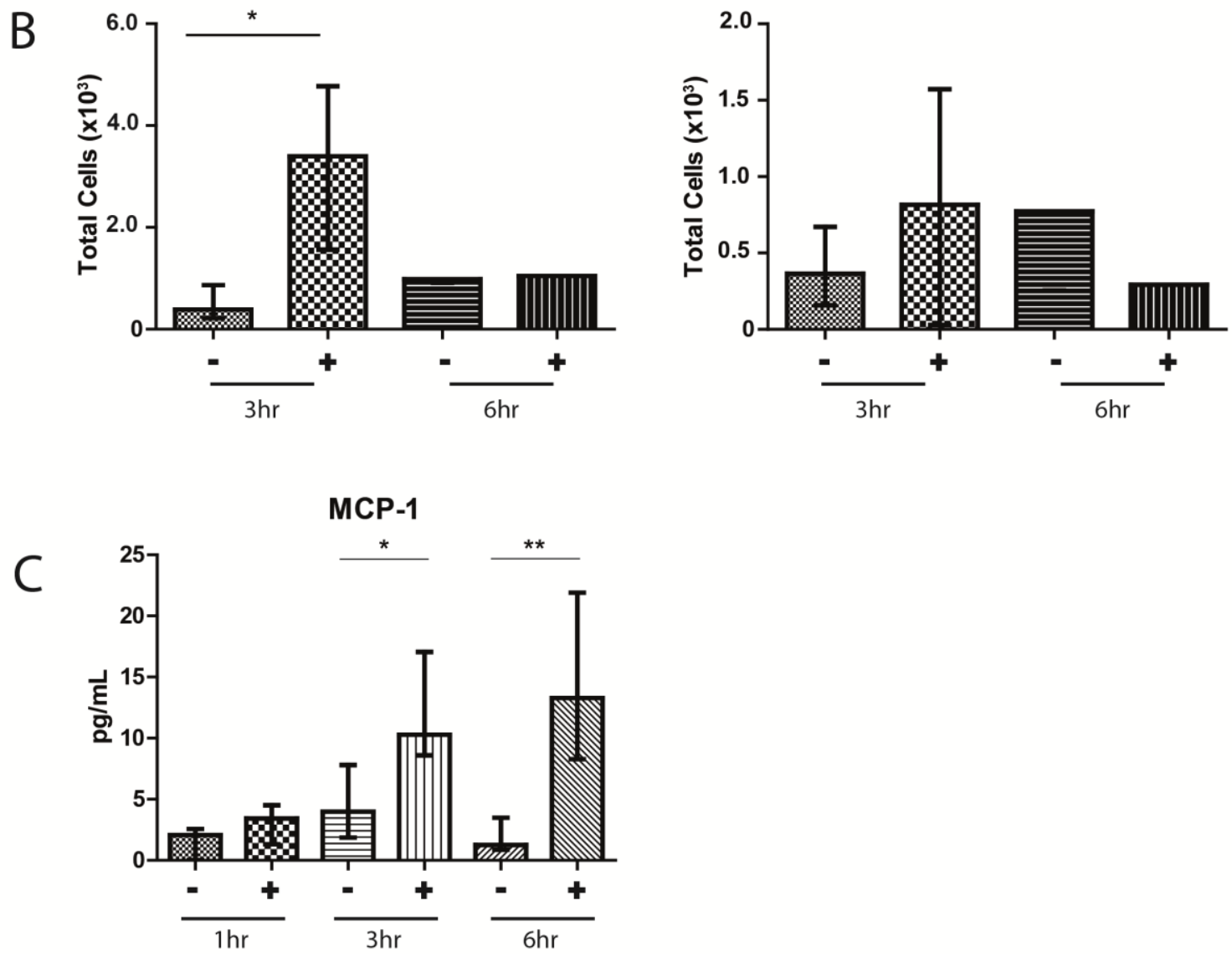
Figure 6a

Neutrophils

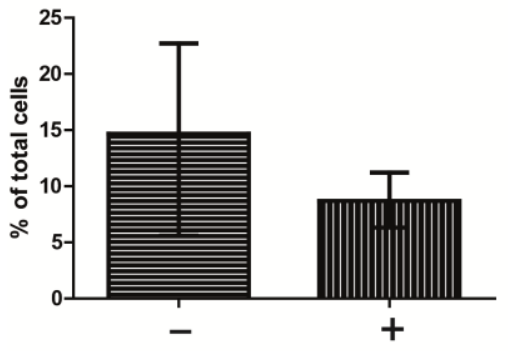

NK Cells

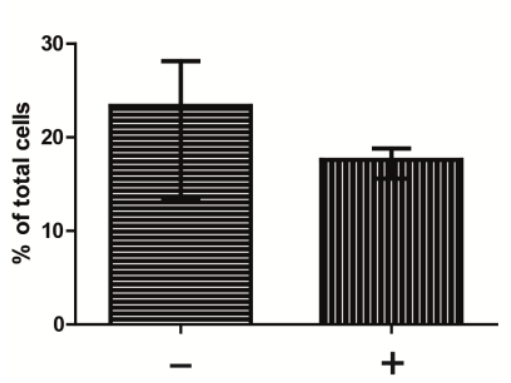

CD4 T Cells

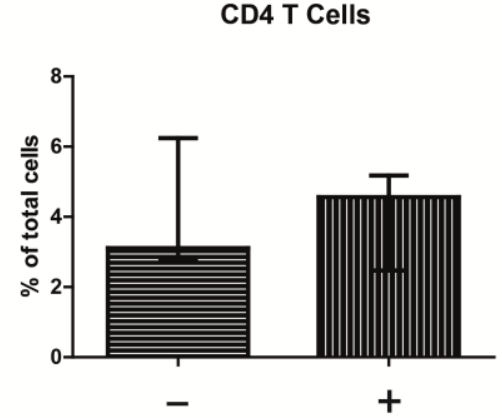

CD43Lo/His48Hi Monocyte-Macrophages

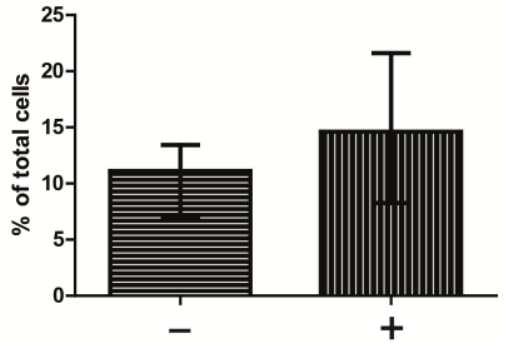

B Cells
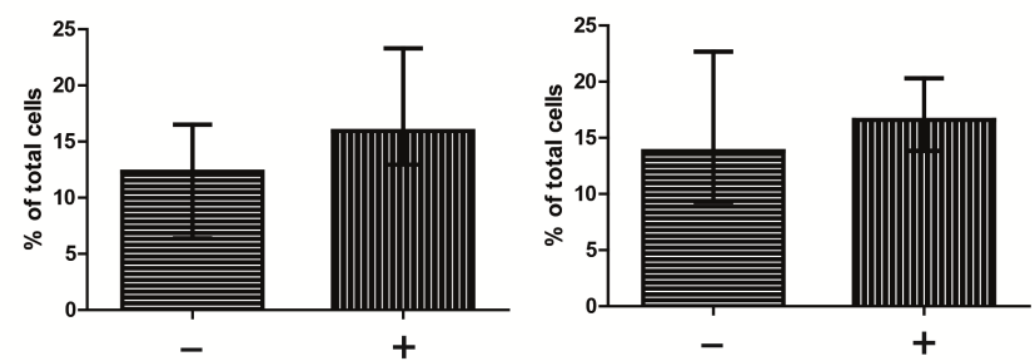

CD43Hi/His48Int-Lo Monocyte-Macrophages

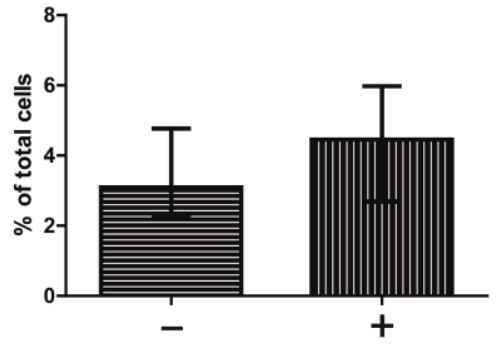

CD3 T Cells

- 
Figure $6 b$
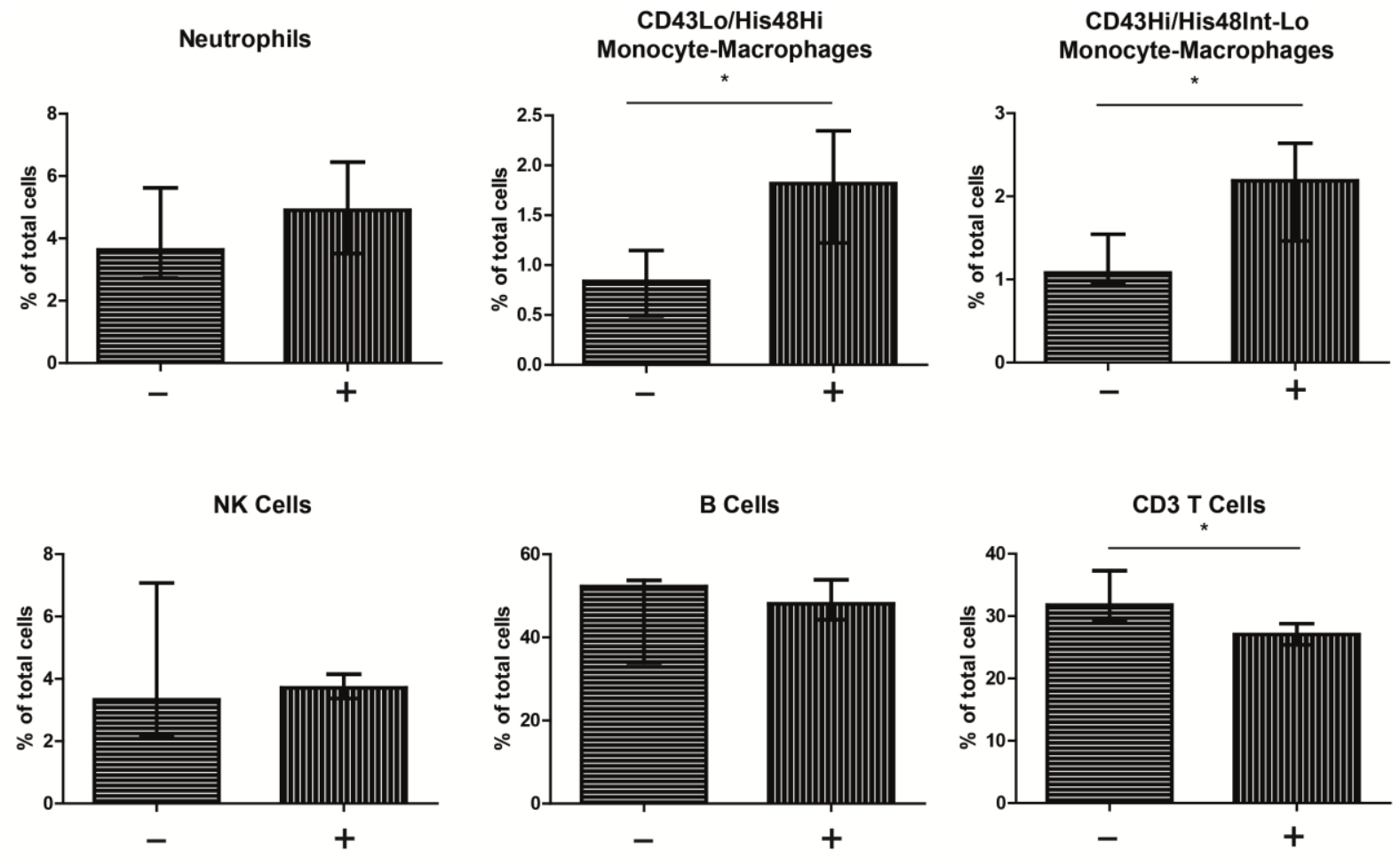

CD4 T Cells

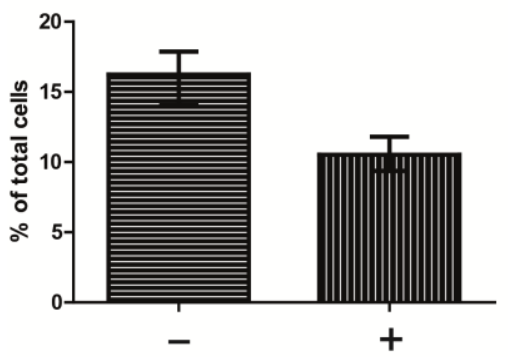

